\title{
Design and analysis of a certain type of engineering environmental management information system
}

\author{
Zeng Lingdong ${ }^{1}$, Dong Peng ${ }^{1}$, Zhou Yujing $^{1}$ \\ ${ }^{1}$ Department of Management Engineering and Equipment Economics, Naval University of Engineering, Wuhan, Hubei, 430033, China
}

\begin{abstract}
A certain type of engineering environmental management information system (referred to as the system) has been developed for many years, but there are not many construction cases. Domestic and foreign companies and enterprises have little research on this type of engineering system construction plan, and the knowledge base of historical experience and lessons is less. The design analysis of the engineering system construction scheme has practical significance and value. The system construction design adopts large-scale joint control technology to integrate all environmental protection subsystems into an organic whole, realize information sharing and collaborative work, realize remote monitoring and control of process equipment, and realize dynamic and online management of equipment information. Eventually, a certain type of engineering achieve the goals of intelligent control, unmanned duty, and controllable operation.
\end{abstract}

\section{Introduction}

The environmental management system is an important part of an integrated management information system. It manages and controls ventilation, electricity, water supply and drainage, temperature and humidity, fire protection and other process system equipment. The composition of a certain type of engineering environmental management system includes systems such as process, equipment monitoring, equipment management, support training. The process system part includes ventilation, power supply and distribution, water supply and drainage, temperature and humidity control, fire protection and other systems. The equipment monitoring part includes ventilation, power supply and distribution, water supply and drainage, temperature and humidity, fire protection linkage and other systems. The equipment management system can include procurement, operation and maintenance, accessories and authority management systems. The support training can include system simulation training and emergency support training. The framework of the system is shown in Figure 1.Environmental management system design generally includes process system design, monitoring design, equipment management design, support training design and so on. This paper focuses on the design and analysis of the control system (system integration) and monitoring system.

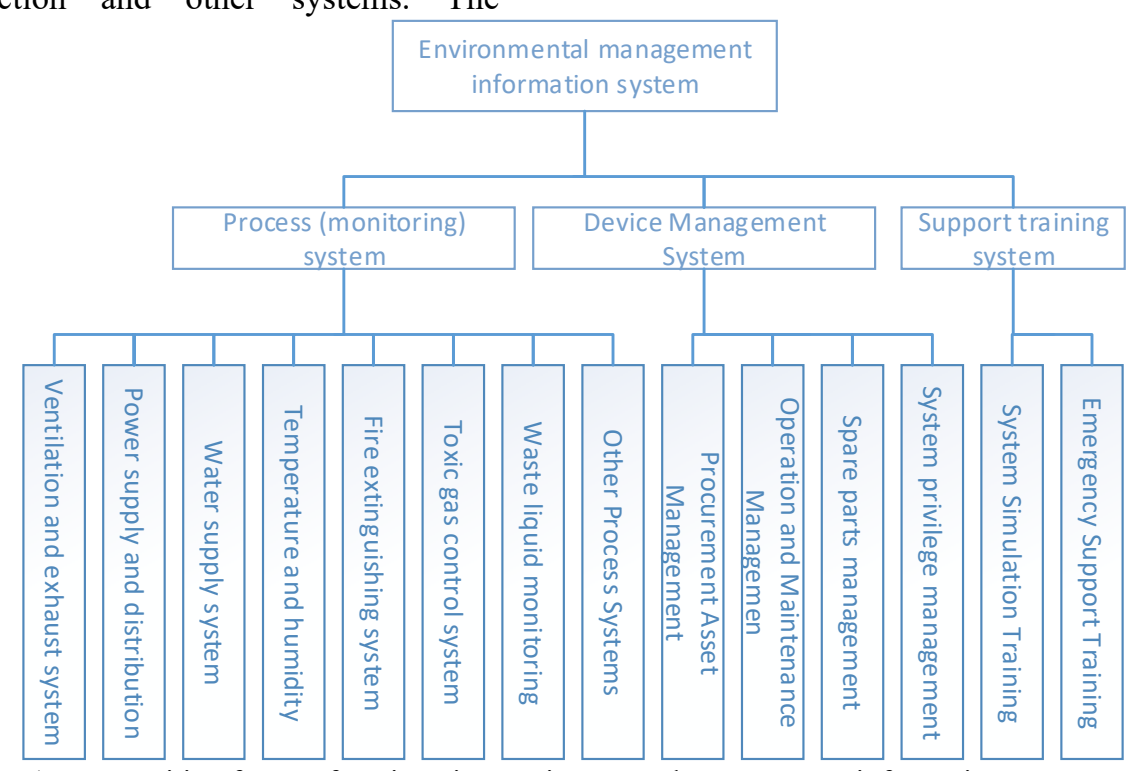

Fig. 1. Composition frame of engineering environmental management information system. 


\section{Overall design analysis}

\subsection{System function design and analysis}

The design of the environmental management system should meet the functional requirements of five aspects.

2.1.1 Realize the scientific configuration of each process system. Meet the needs of activities in the project; Meet the needs of the safety and survival of the personnel in the project (various working conditions); reduce the consumption of resources such as manpower and material resources.

2.1.2 Realize the intelligent control of each process system equipment. Realize the information sharing and collaborative work of each subsystem; realize the intellectualization of the engineering environment guarantee.

2.1.3 Realize the information and dynamic online management of process system equipment; each unit (department) manages equipment scheduling, maintenance, procurement and other matters in a timely and efficient manner through the terminal.

2.1.4 Realize intelligent response to engineering accidents without human intervention. When there are accidents such as power outage, fires, pipe bursts, etc., in the project, corresponding intelligent treatments will be made according to different accident states to improve the response speed of the abnormal state of the project.

2.1.5 Realize the seamless integration of various process system data, information and other resources into the information system of comprehensive engineering management, and improve the ability of integrated comprehensive engineering management.

\subsection{System objective design and analysis}

The design of the environmental protection system scheme should follow six principles.

2.2.1 The controlled equipment runs continuously and reliably. Ensure reliable monitoring of equipment in the project; Real-time reflection of the status of the controlled equipment; Strong stability of the monitoring system; 24-hour uninterrupted operation of the monitoring equipment (the failure rate is less than 5\%).

2.2.2 The controlled area is divided reasonably. The system design should achieve decentralized control and centralized management; the controlled equipment of each sub-station should not be too much (causing heavy load and increased failure rate) or too little (causing waste of resources).
2.2.3 The monitoring parameters of the controlled equipment are comprehensive. The monitoring parameters are set according to the requirements of each system; Provide comprehensive monitoring data for various professionals.

2.2.4 Simple and convenient software interface; Clear operation process (to reduce misoperations).

2.2.5 Taking into account advancement, compatibility and scalability. Easy for upgrade and secondary development; the monitoring system software should have high versatility.

2.2.6 It is convenient for later use, maintenance and management. The system design should include fault self-diagnosis and device hot-plug (on-line replacement) functions.

\subsection{Design and analysis of process system}

When designing the process system, three aspects of redundancy, survival and intelligence should be considered.

Redundancy: considering the number, performance, capacity and other redundancy of equipment; The ventilation system should consider full redundancy (to avoid equipment failure and unable to meet the ventilation demand); In the power supply system, the distribution system, emergency power device and backup power should consider full redundancy; Temperature and humidity systems in important areas should consider $100 \%$ or $200 \%$ redundancy (to meet the requirements of temperature and humidity accuracy and maintenance calibration)

Survival: consider the needs of personnel survival (in case of accidents, avoid the loss of personnel and equipment in the project); the ventilation system should supply oxygen to the isolation area in the isolation ventilation mode in time; When toxic substances leak in special areas, the emergency ventilation should be activated.

Intelligent: when the system is integrated, the equipment monitoring system should fully control the process system; The power supply system should be designed according to the power station automation design principles of the State Grid Corporation of China (the power station should realize intelligent and unmanned operation); In case of power failure of the external grid, the power supply system should realize uninterrupted power supply for important loads (the backup power system can restore power supply in a very short time).

\subsection{Design and analysis of equipment management and support training system}

Equipment management design is the dynamic and online management of equipment information. The 
equipment management system must not only support smart devices that comply with Foundation Fieldbus and HART protocols, but also support traditional devices. The AMS server realizes management functions, including information acquisition, equipment configuration, equipment diagnosis, equipment browsing, event recording and other functions. Equipment management design includes operation and maintenance, spare parts, system permissions and other modules. The support training system is used to train emergency support capabilities, and computer simulation technology should be used to achieve training in operations, maintenance, command, emergency response and supervision. Users and managers quickly become

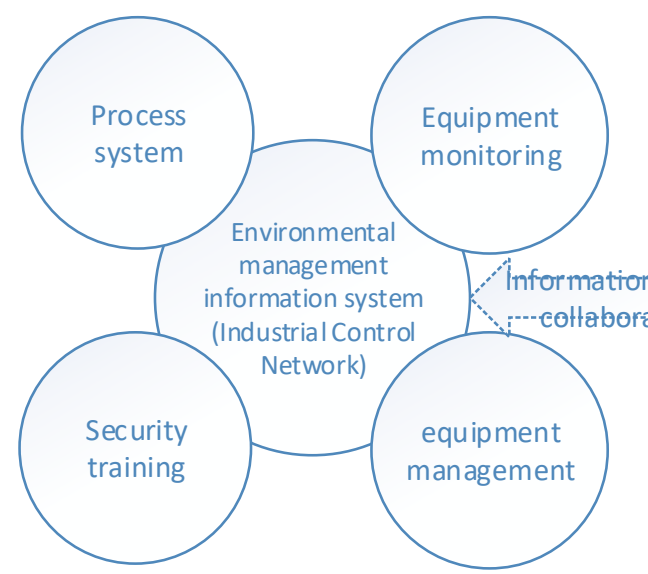

Fig. 2. Relationship between environmental management system and integrated management system.

Control design refers to the integrated design of the process system. The system scheme design can adopt large-scale joint control technology. The advantage of a large-scale joint control system is the integration of independent equipment and systems (through a highly reliable fully redundant control system). The equipment and system can be designed in a control platform to integrate process equipment such as fans, air valves, water pumps, water valves, power supply circuits, lighting circuits, electrical background controls, fire detectors, temperature and humidity sensors. It should realize the inter-system interlocking of equipment to improve accident response capacity; simplify the electrical control of the process system; reduce the failure rate of the control system.

The large-scale joint control system is not only a control system, but also a management system. The control system should have strong capabilities of equipment management, data service and comprehensive information integration. The information of the process system equipment in the project should be dynamic and online; the project management and command can understand the project status in real time. Resolve problems promptly. The specific analysis is as follows.

The control system consists of control nodes (including control stations and process control network communication interfaces, etc.), operating nodes (including engineer stations, operator stations, configuration servers and global engineer stations, data servers and man-machine conversation interface stations) and system networks (including I/O bus, process control familiar with and master the environmental protection system through training.

\section{Control system design and analysis}

\subsection{Overall design analysis}

The environmental management information system (industrial control network) accepts orders from the integrated management information system (business information network) and uploads information. Physical isolation can be used between the two networks. The relationship is shown in Figure 2.

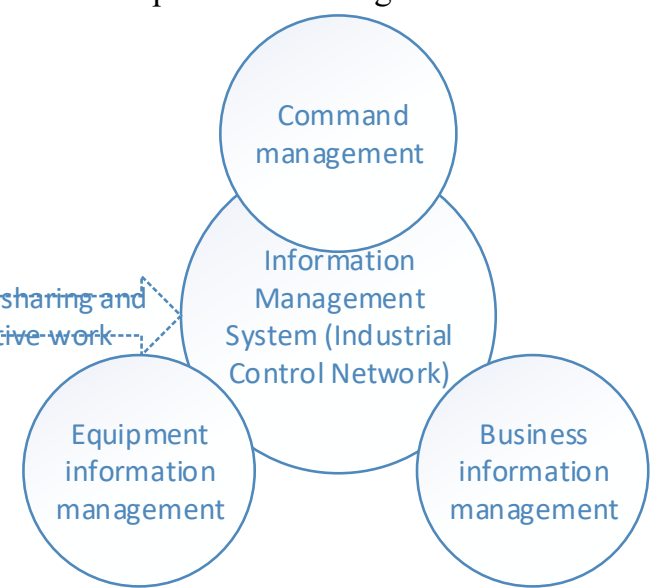
network management, etc.), etc.

The enterprise management network connects the management node; Obtains the control system information from the process information network (through the management server); Manages or remotely monitors the information generation process.

The process information network connects all operating nodes such as engineer stations, operator stations, configuration servers (main engineer stations) and data servers in the control system. The process information network transmits information such as historical data, alarm and operation records among operation nodes. The application site of the process information network can access real-time (historical) information and issue operating instructions (through data servers in the operating domain).

The I/O bus (expansion bus and local bus) is an internal communication network of control stations. The expansion $\mathrm{I} / \mathrm{O}$ bus connects the controller and various communication interface modules (such as I/O connection module, PROFIBUS communication module, serial communication module, etc.); the local $\mathrm{I} / \mathrm{O}$ bus connects the controller and the $\mathrm{I} / \mathrm{O}$ module (or connects the I/O connection module and I/O module). The I/O bus (expansion bus and the local bus) are redundantly configured. 


\subsection{Design analysis of system structure hierarchy}

According to the structural characteristics of the large-scale joint control system, the system design can be divided into four layers: Enterprise System, Operating management, Supervisory Control, and Basic Control, realize different functions respectively. See figure 3 for the control system structure.

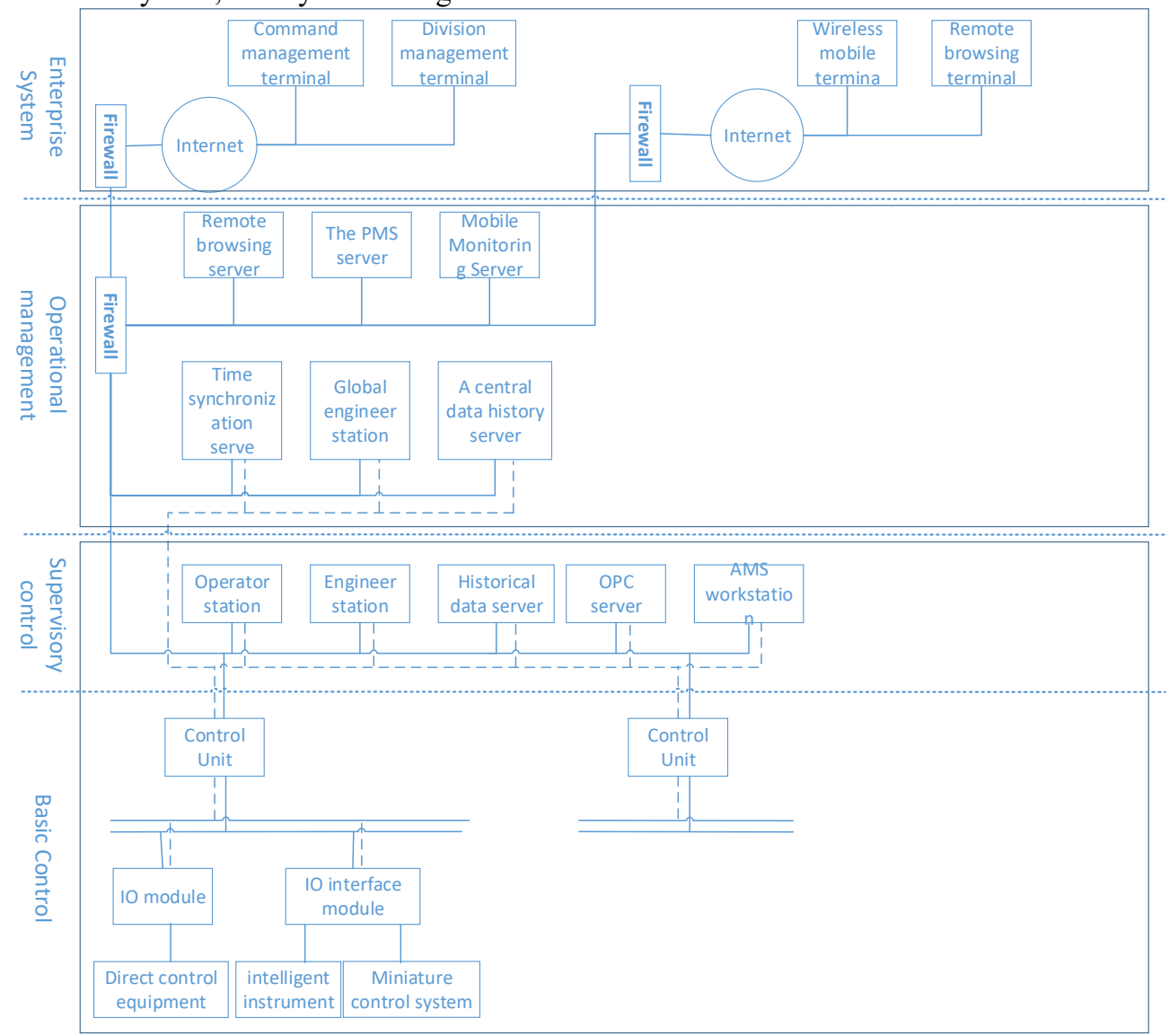

Fig. 3. Control system structure hierarchy diagram.

The enterprise layer realizes comprehensive management functions. According to the data and information of the operation management (displayer on the command terminal or the large screen in the hall), the project commander can grasp the real-time status of the process system, personnel and equipment, and make various decisions in time. Sub-department personnel (finance, procurement, security, etc.) handle the business information of the department in time according to their respective authority; relevant leaders of the higher-level agency (departments) browse various authorization information in the project through mobile or remote terminals. Terminals such as command management, sub-department management, remote browsing, and wireless mobile should be configured.

The operations management layer provides data information services (data support and order acceptance) to the enterprise layer; Realizes the maintenance and management of the full control system. The operations management layer (process information network) mainly provides information services and does not participate in specific equipment control. The operations management layer should configure remote browsing, PMS(Policy Management), and mobile monitoring servers to meet the data support needs of the enterprise layer. Time synchronization server, global engineer station and central historical data server should be configured to meet the functional needs of global system maintenance.

The supervisory control layer realizes the data support and order acceptance of the operation management layer; Implement data and device services; Realize the remote monitoring and control of the on-site control layer equipment (data acceptance and instruction issuance), and realize the integration of third-party systems. The design of the supervisory control layer can include operator stations, engineer stations, historical data servers, OPC servers and AMS(Asset Management System ) workstations.

The field control layer is managed and controlled by the area controller. The field control layer accepts the instruction of the supervisory control layer and uploads the collected data; executes the instructions from the supervisory control layer and accepts the data from the sensor. The field control layer is composed of field controllers, communication modules, remote IO acquisition modules, direct control equipment, smart meters, small control system and other parts. 


\section{Monitoring system design and analysis}

The equipment monitoring part realizes the remote monitoring and control of various process system equipment such as ventilation, power supply and distribution, water supply and drainage, temperature and humidity, fire protection. The monitoring system includes ventilation, power supply, water supply and drainage, temperature and humidity monitoring systems and other systems.

\subsection{Ventilation monitoring system}

The ventilation monitoring system controls the ventilation system equipment to meet the engineering functions according to the ventilation process. The system includes fan (valve) control cabinet, sensor (pressure difference, wind speed, temperature and humidity, etc.), dehumidifier (air conditioner) interface and other parts. The ventilation monitoring system includes monitoring systems such as ventilation and air conditioning, accident exhaust, poison filtration, and oxygen generation.

The monitoring centre should be able to reflect the operating parameters and equipment status. Operational records should be stored on the monitoring computer. The parameters to be monitored in the ventilation and air conditioning system include the opening/closing of ventilation valves, the opening/closing of humidification valves, the wind speed of main ventilation pipes, the manual/automatic status of the ventilation and air conditioning equipment, the start/stop control and operation status of the ventilation and air conditioning equipment, the frequency of the variable frequency fan, the fault feedback of the ventilation and air conditioning equipment, etc. Ventilation and air conditioning equipment (all to be controlled) should be designed with remote control functions. Automatic control (interlocking and sequence) includes: air valve and fan interlock (open the air valve when the fan starts; close the air valve after the fan is turned off); The cooling water valve control of the air conditioner is connected to the control system of the air conditioner itself. The running time can be set and modified (to distinguish wet/non-wet seasons); the air valve should automatically adjust the operation according to the concentration of pollutants, negative pressure state, temperature and humidity. In case of accident ventilation, ventilator switches should be set indoors and outdoors respectively. The ventilation device should be interlocked with the harmful gas concentration alarm switch; there should be nearby and remote alarms.

\subsection{Power supply and distribution monitoring system}

In case of power failure of the external network or failure of the internal system, the important equipment should be handled intelligently (without human intervention). The substation, diesel generator set, emergency power device, power distribution room, etc. are designed as an organic whole. The power supply and distribution monitoring system should include remote monitoring functions (power distribution system, lighting system, emergency power system and backup power system, etc.).

The power automation system can monitor the grid voltage, current, temperature and other parameters of the substation. Remotely control and manage some circuit breakers. The monitoring system should communicate with the power supply system of the substation through the communication interface to realize the remote monitoring of the substation. The monitoring signal is displayed on the control computer in real time and transmitted to the control hall computer; the data information of the substation is interacted through the controller of the control hall to realize data sharing. Combined with the monitoring data information, the power distribution system is transformed and distributed. The lighting power supply should be provided by division (function division), and the corresponding lamps should be turned on (turned off) according to corresponding control rules; the monitoring system should be able to remotely turn off the lighting system.

\subsection{Water supply and drainage monitoring system}

The water supply and drainage monitoring system shall meet the demand for water in all cases. The water supply and drainage monitoring system should include cooling, living, fire protection, general pressure drainage, heating, sewage treatment and other subsystems.

The man-machine interface of the monitoring centre should be able to reflect the operating parameters and equipment status; the monitoring computer should store operation records. The water supply and drainage equipment should be designed with a remote control function, which can only be enabled when the "manual/automatic switch" in the field control cabinet is switched to "automatic". The interlocking and sequential control should be realized: the valve and the water pump are interlocked (open the corresponding valve first when starting the water pump, close the valve after closing the water pump); Each pump room is set by the control cabinet to set the control mode; The data is connected to the monitoring centre; The monitoring centre sets the corresponding functions (water supply and drainage system requirements); Up to two pump rooms work at the same time; The running time can be set and modified (when automatically controlled).

\subsection{Temperature and humidity monitoring system}

The temperature and humidity data are fed back to the ventilation monitoring system; the ventilation monitoring system adjusts according to the data. Temperature and humidity transmitters are set in important areas to collect temperature and humidity changes on site. Relevant alarm functions should be 
designed. The temperature and humidity transmitter can be integrated with an analog input module; After the input is processed by the controller, it is sent to the primary and secondary servers of the communication network layer for recording and archiving (the data is stored for at least 3 years; It can be monitored through the operator station).

\section{Conclusion}

The construction of an environmental management information system can organically integrate various process systems, realize information sharing and collaborative work, and improve the efficiency of project management and guarantee. The engineering environment management system can realize the functions of intelligent control, unmanned duty and controllable operation. Intelligentization can improve the linkage efficiency of engineering environmental management system; Unmanned duty can reduce the investment of manpower and material resources in the engineering environmental management system. Controllable operation can reduce the uncontrollability of engineering environmental management system.

\section{Reference}

1. Chen Hong. (2015)Building Automation Technology and Application [M]. China Machine Press, Beijing.

2. Zhang Yun, Xu Jinbiao. ( 2017)Building Intelligent System [M]. Tsinghua University Press, Beijing.

3. Fu Haijun. (2017)Building Automation [M]. China Machine Press, Beijing.

4. Shen Ye. (2014)Building Automation Technology and Engineering [M]. China Machine Press, Beijing.

5. LIU Xiaozhen. (2018)People's Environmental Safety Technology [M]. Science Press, Beijing.

6. Lu Guiqing. (2019)Construction enterprise management information practical case study [M]. China Building Industry Press, Beijing.

7. Xin Jiangyan. (2017)Enterprise Information Planning [M]. Tsinghua University Press, Beijing.

8. LIU Xijian. (2013)Enterprise Information Management Practice [M]. Petroleum Industry Press, Beijing.

9. Zuo Meiyun. (2014)Information System Project Management [M]. Publishing House of Electronics Industry, Beijing. 